\title{
Acetylcholinesterase Activity in Partially Isolated Cerebral Cortex after Prolonged Intermittent Stimulation
}

\author{
Joyce A. Duncan, Lester T. Rutledge, and Edward F. Domino ${ }^{1}$ \\ Department of Physiology and Pharmacology, The Unizersity of \\ Michigan Medical School, Ann Arbor, 48104
}

Reccived September 29 ; revision received

October 26, 1967

\begin{abstract}
Acetylcholinesterase (AChE) levels were determined in control samples of cat cerebral cortex, in partially neuronally isolated (undercut) cortex, and in undercut or intact cortex that had received long-term intermittent electrical stimulation. Assay of $\mathrm{AChE}$ activity was based on an automatic titration method using methalcholine as substrate. Tissues from ten of 15 undercut cerebral cortices showed the expected decrease in $\mathrm{AChE}$. Long-term intermittent electrical stimulation of undercut cortex prevented the expected decrease in AChE in seven of 12 cortices. Previous data showed that similar long-term stimulation could prevent some electrical manifestations of supersensitivity. The present findings implicate, in part, a cholinergic system in the phenomenon of cortical supersensitivity.
\end{abstract}

\section{Introduction}

Previous studies have demonstrated that undercut portions of cerebral cortex with pial circulation intact survive and develop supersensitivity to electrical stimulation. This supersensitivity may be prevented by long-term periodic electrical stimulation with currents below threshold for eliciting afterdischarge (9). Cerebral cortex which has been partially "isolated" by subpial section along three sides and undercut, also survives and becomes highly sensitive to electrical stimulation and to acetylcholine (Ach) topically applied (1). A relationship between supersensitivity and an alteration in the ACh system has been suggested (8). This possibility is also supported by evidence that partially isolated cortex shows a marked decrease in acetylcholinesterase (AChE) activity (1). If there is such a relationship, determination of the $\mathrm{AChE}$ levels of stimulated undercut cortex might show a correlation and explain the prevention of supersensitivity.

1 Supported in part by USPHS grants NB-04119 (to L.T.R.) and NB-01311 (to E.F.D.),

The authors are grateful to $\mathrm{Mr}$. Jon Frappier for his conscientious efforts in the AChE assay. 


\section{Methods}

Experiments were performed on 36 cats. Chemical analyses were carried out on these and on 22 unoperated controls. All surgical procedures were performed under sodium pentobarbital anesthesia using aseptic techniques.

In group I (15 cats) the marginal gyrus was unilaterally undercut at least 10 weeks prior to the chemical analyses. Undercutting severed all subcortical fibers $3-4 \mathrm{~mm}$ below the cortical surface for a distance of about $20 \mathrm{~mm}$. This group did not receive electrical stimulation. The nine animals in group II had unilaterally implanted cortical stimulating electrodes over the intact marginal gyrus. The electrodes consisted of pairs of platinum wires embedded in a plastic button with the tips $2-3 \mathrm{~mm}$ apart, oriented parallel to and $4-5 \mathrm{~mm}$ from the midline. In the 12 animals of group III, the marginal gyrus was undercut and stimulating electrodes were implanted in the middle of the undercut region.

Electrical stimulation began 1 week after surgery for the cats in groups II and III. The stimulation consisted of 20 daily applications of a 2 -sec train of $1 \mathrm{msec}$ pulses at $50 / \mathrm{sec}$ spaced $1 \mathrm{~min}$ apart, applied 6 or 7 days per week. All together, 400 stimuli at $0.6 \mathrm{mamp}, 400$ at 0.8 mamp and 200 at 1.0 mamp, all constant current, were applied to each animal in groups II and III. The intensities presumably were below threshold for inducing electrical afterdischarge (9). The time elapsing between surgery and the $\mathrm{AChE}$ assay was about 10 weeks. One week after the last stimulation (10 weeks after the undercutting procedure for group I animals), each cat was anesthetized with chlorolose and brain pieces $15 \times 5 \times 3-4 \mathrm{~mm}$ were removed for analyses from the operated cortex along with a corresponding piece of homotopic "intact" cortex. The tissues were immediately frozen in dry ice and remained frozen until the chemical analyses were performed 4 hours to 1 week later.

The procedure employed for the analyses of $\mathrm{AChE}$ activity was a combination of the Jørgensen and Jensen-Holm methods $(5,6)$. Tissue homogenates were made with saline $(141 \mu \mathrm{M} \mathrm{NaCl}, 1: 10)$ and $1 \mathrm{ml}$ of the homogenate, the equivalent of $100 \mathrm{mg}$ of brain tissue, was diluted 1:30 in distilled water. This mixture was then placed in a water bath maintained at $37.5 \mathrm{C}$ and the $\mathrm{pH}$ adjusted to 7.4 with $\mathrm{NaOH}(0.1$ or $0.5 \mathrm{~N})$. A total of $8.3 \mathrm{mg}\left(4.3 \times 10^{-4} \mu \mathrm{mole} / \mathrm{g}\right)$ of acetyl- $\beta$-methylcholine chloride (methacholine) was then added to the mixture. The acid liberated from methacholine hydrolysis was neutralized and the $\mathrm{pH}$ maintained with $\mathrm{CO}_{2}$-free $\mathrm{NaOH}$ by means of an automatic recording titrator (Radiometer, Inc.). A homogenated blank was determined first and each analysis then followed for 5-10 min. Cholinesterase activity was calculated from the quantity of $\mathrm{NaOH}$ added per unit time and expressed as $\mu$ moles/g/hr of substrate hydrolyzed. Absolute rates were equivalent to enzymatic hydroly- 
sis of methacholine plus its nonenzymatic hydrolysis. Nonenzymatic hydrolysis in most cases was insignificant, but when it was measurable it was subtracted from the absolute rates.

The chemical analyses were made on tissues from the 36 experimental animals and on those from 22 unoperated control animals used to verify the accuracy of the method. Tissue samples from control animals were analyzed with or without accompanying experimental samples. All tissue samples were coded with the identities unknown until after the chemical analyses were completed.

\section{Results}

Icvels of $\mathrm{AChE}$, expressed as $\mu$ moles $/ \mathrm{g} / \mathrm{hr}$ of substrate hydrolyzed, for the three groups, are summarized in Table 1 and Fig. 1. For the 15 animals in the nonstimulated undercut group I, the operated side showed a statistically significant decrease in $\mathrm{ACh}$ activity $(p=<0.01>0.001)$ when compared with the intact side (3). Five of the 15 cats failed to show a difference between the two sides. These are shown separately as group IA (Table 1 and Fig. 1). A possible explanation for these five exceptions

TABLE 1

AChE Activity Levels in Undercut (I), Stimulated Nonundercut (II), Stimulated Undercut (III), and Control Cortices ${ }^{a}$

\begin{tabular}{|c|c|c|c|c|c|c|c|c|}
\hline \multirow[b]{2}{*}{$(N)$} & \multicolumn{3}{|c|}{$\mathrm{I}^{b}$} & \multirow{2}{*}{$\frac{\text { II }}{-}$} & \multicolumn{3}{|c|}{ Ill } & \multirow{2}{*}{ Controls } \\
\hline & $\begin{array}{r}\mathrm{A} \\
(5)\end{array}$ & $\begin{array}{c}\mathrm{B} \\
(10)\end{array}$ & $\begin{array}{c}A+B \\
(15)\end{array}$ & & $\begin{array}{l}A \\
(5)\end{array}$ & $\begin{array}{c}\mathrm{B} \\
(7)\end{array}$ & $\begin{array}{c}A+B \\
(12)\end{array}$ & \\
\hline $\begin{array}{l}\text { Unoperated } \\
\text { Side }\end{array}$ & $\begin{array}{l}\quad 62.4^{c} \\
\pm 2.7\end{array}$ & $\begin{array}{r}66.6 \\
\pm 1.9\end{array}$ & $\begin{array}{r}65.2 \\
\pm 1.9\end{array}$ & $\begin{array}{r}65.4 \\
\pm 1.7\end{array}$ & $\begin{array}{r}63.2 \\
\pm 2.2\end{array}$ & $\begin{array}{r}60.5 \\
\pm 2.5\end{array}$ & $\begin{array}{r}60.8 \\
\pm 1.7\end{array}$ & 600 \\
\hline $\begin{array}{l}\text { Operated } \\
\text { Side }\end{array}$ & $\begin{array}{r}63.1 \\
\pm 4.7\end{array}$ & $\begin{array}{r}50.5 \\
\pm 2.6\end{array}$ & $\begin{array}{r}54.7 \\
\pm 2.8\end{array}$ & $\begin{array}{r}62.2 \\
\pm 1.8\end{array}$ & $\begin{array}{r}46.9 \\
\pm 2.4\end{array}$ & $\begin{array}{r}60.3 \\
\pm 2.3\end{array}$ & $\begin{array}{r}54.6 \\
\pm 2.5\end{array}$ & \pm 1.1 \\
\hline$p$ value $\mathrm{e}^{d}$ & NS & $<0.001$ & $\begin{array}{l}<0.01 \\
>0.001\end{array}$ & $\begin{array}{l}<0.3 \\
>0.2\end{array}$ & & NS & $\begin{array}{l}<0.1 \\
>0.05\end{array}$ & \\
\hline$p$ value $^{e}$ & & & 0.05 & 0.03 & & & NS & \\
\hline
\end{tabular}

a Expressed in terms of $\mu \mathrm{M} / \mathrm{g} / \mathrm{hr}$ of substrate hydrolyzed.

${ }^{b}$ Groups I and III animals with no change in $\mathrm{AChE}$ as a result of undercutting or stimulation indicated as " $\mathrm{A}$ " those with a changes as " $\mathrm{B}$."

$c$ Means and standard errors.

$d t$-Test probability valucs comparing differences between means of unoperated and operated sides; $\mathrm{NS}=$ not significant.

$e$ Comparing controls with unoperated sides. 


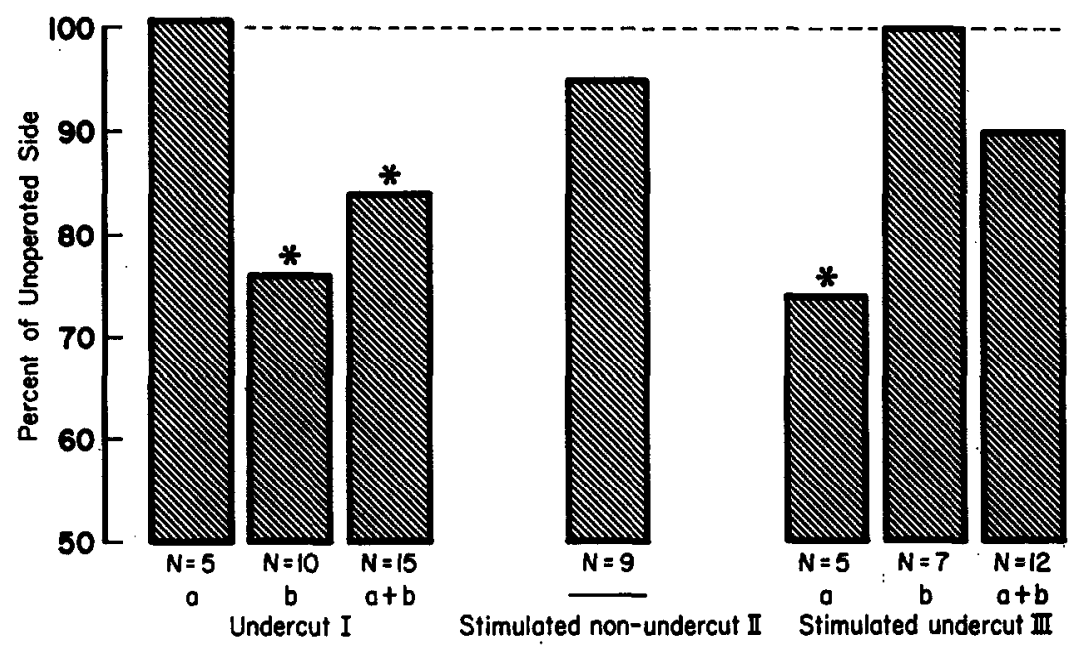

Fig. 1. AChE levels of undercut, stimulated nonundercut, and stimulated undercut cortices expressed as percent of AChE level of the contralateral unoperated cortex in each group. Those animals with no change in $\mathrm{AChE}$ as a result of undercutting or stimulation are indicated as " $a$," those showing a change as "b." Asterisks indicate differences significant $(p<0.05)$ between operated and unoperated sides.

may be that supersensitivity does not develop in all undercut (9) or all "isolated" cortices $(2,11)$. No electrophysiological experiments were performed on these animals, thus the validity of this supposition could not be proved.

In group II animals which had received daily electrical stimulation but whose brains had not been undercut, the AChE activity of the stimulated side was not significantly different from the nonstimulated side $(p=$ $<0.3>0.2$ ).

For the 12 animals in the stimulated-undercut group III, the $\mathrm{AChE}$ activity on the operated side was not significantly different from that on the intact side $(p=<0.1>0.05)$. Five of these animals, however, still showed a difference between the two sides and these are depicted separately (Table 1 and Fig. 1). Failure to prevent supersensitivity by prolonged intermittent electrical stimulation occurred in $18 \%$ of the animals in a previous study using the same procedures (9).

An apparent increase in $\mathrm{AChE}$ level of certain unoperated cortices is seen in Table 1. A $t$-test (group comparison) between the mean $\mathrm{AChE}$ levels of the unoperated sides of groups I and II (group I, 65.2 and group III, 60.8) showed no significant difference $(p=\langle 0.1>>0.5)$ and thus the null hypothesis could not be rejected. When the unoperated sides of group I were compared with the controls (means of 65.2 and 60.9 ), the difference was significant at the 0.05 level. A similar test of group II 
with controls was also significant $(p=0.03)$. These findings warrant caution in treating cortex contralateral and homotopic to the operated side as if it were normal and "intact." Indeed, degeneration of collosal fibers in all undercut preparations means homotopic cortex is not "intact."

With these limitations and at this stage of investigation, it seemed most appropriate to compare $\mathrm{AChE}$ levels of the two sides within animals in a group. Thus in Table 1 the most important data are the comparisons made within group I and within group III. A $t$-test of the difference between the unoperated and operated means of group I (65.2 and 54.7) yielded a $p$ value of $<0.01,>0.001$. The null hypothesis is rejected and we conclude that the $\mathrm{AChE}$ level of the undercut cortex was significantly lower than that of homotopic cortex. A similar comparison within group III (means of 60.8 and 54.6) give a $p$ value of $<0.1,>0.05$. The null hypothesis is not rejected and levels of AChE between the sides are not different in the animals that had been electrically stimulated.

\section{Discussion}

Cerebral cortex that has been extensively neuronally isolated for 6-10 months shows a significant decrease in $\mathrm{AChE}$ activity (8). Hebb et al. (4) using histochemical techniques found a reduction of AChE staining 1-5 weeks after only undercutting cerebral cortex. They concluded that the chlorinergic ( $\mathrm{AChE}$ stained) fibers that innervate cortical cells travel to the cortex from deep nuclei or distant cortical regions. Krnjevic and Silver (7) found that cholinergic fibers were mostly in a system of horizontal pathways, particularly U-fibers linking together various cortical areas. The U-fibers connected adjacent gyri, traveling just below and into cortex. Our finding of a significant decrease in the AChE activity in undercut preparations is in agreement with these previous data. The decrease of $24 \%$ (for the ten animals showing a decrease), compared with Rosenberg's and Echlin's $50-60 \%$ (8) might be explained by the fact that undercut cortex is not as completely neuronally isolated. Some corticofugal ("cholinergic") fibers probably entered the arca at the borders of the undercut in our studies.

The effect of long-term electrical stimulation in our experiments was to decrease the expected diffcrence in $\Lambda \mathrm{ChE}$ activity between the undercut and homotopic sides of the brain. Prolonged intermittent stimulation of undercut cortex also has this equilibrating effect on afterdischarge activity (9). This is consistent with the theory of a relationship between the $\mathrm{ACh}$ system and seizure activity (10).

For neuronally isolated cerebral cortex, Sharpless (10) believes the fall in $\Lambda \mathrm{ChE}$ is due to degenerative changes. According to Hebb et al. (4) the loss of corticofugal cholinergic fibers would produce the AChE 
decrease. This certainly applies, although to a somewhat lesser extent, to undercut as opposed to completely neuronally isolated cerebral cortex. However, the effect of long-term electrical stimulation in our experiments could be upon remaining $\mathrm{ACh}$ or $\mathrm{AChE}$ mechanisms or structures. Since long-term stimulation has no effect upon the AChE of nonundercut cortex (group II), the pathological condition of undercutting must be prerequisite for AChE alteration by electrical stimulation. It is emphasized that although the cholinergic system is implicated in denervation supersensitivity of undercut cortex by our experiments, it is probably not the only transmitter system involved.

Partially neuronally isolated, including undercut cortex, becomes supersensitive to $\mathrm{ACh}$ and has reduced $\mathrm{AChE}$ levels. Prolonged intermittent electrical stimulation of undercut cortex can prevent the expected supersensitivity (9) and the decrease in AChE activity. Our experiments suggest that an undefined compensatory mechanism may be established by the long-term electrical stimulation whereby increased neuronal sensitivity to $\mathrm{ACh}$ is prevented.

There are unanswered questions from our studies which prompt caution in drawing conclusions concerning neuronal and chemical mechanisms. Why do some neuronally isolated or partially neuronally isolated cortices fail to develop supersensitivity? If prolonged electrical stimulation can indeed prevent supersensitivity and the expected decrease in $\mathrm{AChE}$ levels as our data seem to show, why isn't the procedure effective in all instances? The apparent increase in AChE levels contralateral to undercut tissue and contralateral to stimulated, nonundercut tissue, is similarly puzzling. In spite of these important unanswered questions this study points toward possibilities of correlating nueronal function and structure with chemical events.

\section{References}

1. Echlin, F. A., AND A. Batrista. 1962. Decreased cholinesterase activity in epileptogenic chronically "isolated" cerebral cortex. Trans. Am. Neurol. Assoc. $87: 190-192$.

2. Echlin, F. A., And J. McDonald. 1954. The supersensitivity of chronically isolated and partially isolated cerebral cortex as a mechanism in focal cortical epilepsy. Trans. Am. Neurol. Assoc. $79:$ 75-79.

3. Fisher, R. A. 1958. "Statistical Methods for Research Workers." Hafner, New York.

4. Hebb, C. O., K. KrnJević, ANd A. Silver. 1963. Effect of undercutting on the acetylcholinesterase and choline acetyltransferase activity in the cat's cerebral cortex. Nature 198: 692.

5. Jensen-Holm, J., H. H. Lausen, K. Milthers, and K. O. Mфller. 1959. Determination of the cholinesterase activity in blood and organs by automatic titration. With some observations on serious errors of the method and remarks of the photometric determination. Acta Pharmacol. Toxicol. 15 : 384-394. 
6. JøRGENSEN, K. 1959. Automatic recording of choline esterase activities. Scand. $J$. Clin. Lab. Invest. 11 : 282-284.

7. KRNJević, K., ANd A. Silver. 1963. The distribution of 'cholinergic' fibres in the cerebral cortex. J. Physiol. London 168: 39-40P.

8. Rosenberg, P., ANd F. A. Echlin. 1965. Cholinesterase activity of chronic partially isolated cortex. Neurology 15: 700-707.

9. Rutledge, L. T., J. B. Ranck, JR., AND J. A. Duncan. 1967. Prevention of supersensitivity in partially isolated cerebral cortex. Electroencephalog. Clin. Neurophysiol. 23 : 256-262.

10. Sharpless, S. K. 1964. Reorganization of function in the nervous system-use and disuse. Am. Rev. Physiol. 26: 357-388.

11. Sharpless, S. K., and L. M. Halpern. 1962. The electrical excitability of chronically isolated cortex studied by means of permanently implanted electrodes. Electroencephalog. Clin. Neurophysiol. 14: 244-255. 